Journal of Case Reports 2017;7(2):127-129

\title{
Primary Tuberculosis of Breast: A Rare Presentation
}

\author{
Rahul Kumar ${ }^{1}$, Silpa Kshetrimayum², Santosh Kumar ${ }^{3}$, Rajiv Garg ${ }^{3}$ \\ ${ }^{1}$ Department of Respiratory Medicine, Medanta: The Medicity, Gurugram, Haryana; ${ }^{2}$ Department of Medicine, RIMS, Imphal; \\ ${ }^{3}$ Department of Respiratory Medicine, King George's Medical University, Lucknow, Uttar Pradesh, India.
}

\section{Corresponding Author:}

Dr. Silpa Kshetrimayum

Email:ksh.silpa@gmail.com

This is an Open Access article distributed under the terms of the Creative Commons Attribution License (creativecommons.org/ licenses/by/3.0).

Received

Accepted

Published

April 5, 2017

\section{Introduction}

Breast tuberculosis (TB) is a rare form of extrapulmonary TB first described by Sir Astley Cooper in 1829 [1]. Although over one billion people suffer from TB worldwide, breast TB is an extremely rare entity. Isolated TB of the breast varies from $0.10 \%$ to $0.52 \%$ [2]. It has been scarcely reported even in countries with a high incidence of tubercular infection. This is explained by a noticeable resistance of the mammary tissue to the Mycobacterium tuberculosis [3].

\section{Case Report}

A 23-year-old female presented with an abscess in upper inner quadrant of right breast for three months. Local temperature was raised. Nipple areolar complex was normal. There was no axillary lymphadenopathy. Patient gave no history of cyclical mastalgia or nipple discharge. There was no history of breast carcinoma or tuberculosis in her family. On evaluation, total leucocyte count (TLC) and erythrocyte sedimentation rate (ESR) were raised. Chest X-ray was normal [Fig.1]. Tuberculin skin test was negative. Sputum for acid fast bacilli (AFB) smear was negative. Breast mammography revealed an oval irregular thick walled low level echo complex cystic mass at 3 O'clock position in retro-areolar position [Fig.2]. It measured 26x11 $\mathrm{mm}$ in size. Pus from the abscess was subjected for TB-PCR and Mycobacterium tuberculosis was detected. Standard anti-tubercular therapy was administered as per weight. The abscess reduced in size. Mammography after 2 months showed reduction in size of the abscess [Fig.3]. Follow up mammography after 12 months of ATT showed complete resolution of the abscess [Fig.4].

\section{Discussion}

Isolated tuberculosis of the breast is rare, even in developing countries where pulmonary and other forms of extra-pulmonary tuberculosis are common. The incidence of isolated TB of the breast remains low, ranging from $0.10 \%$ to $0.52 \%$. In tuberculosis endemic countries like India, the incidence represents $3 \%$ to $4.5 \%$ of all mammary pathologies [4]. The Western world accounts for 


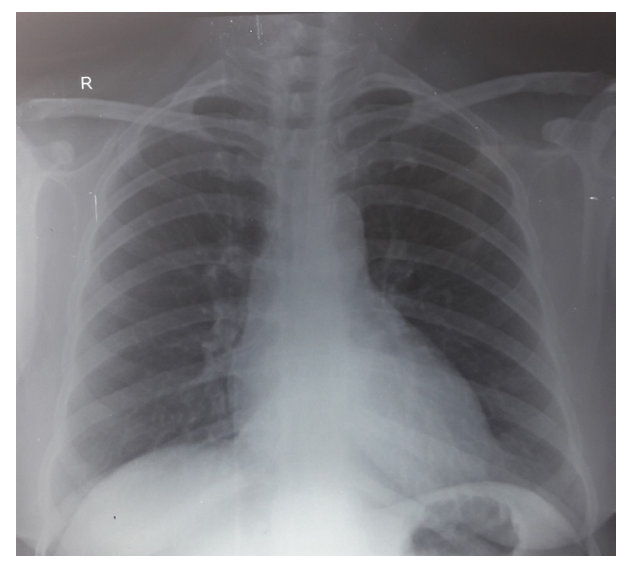

Fig.1: Chest $X$-ray $P A$ view.

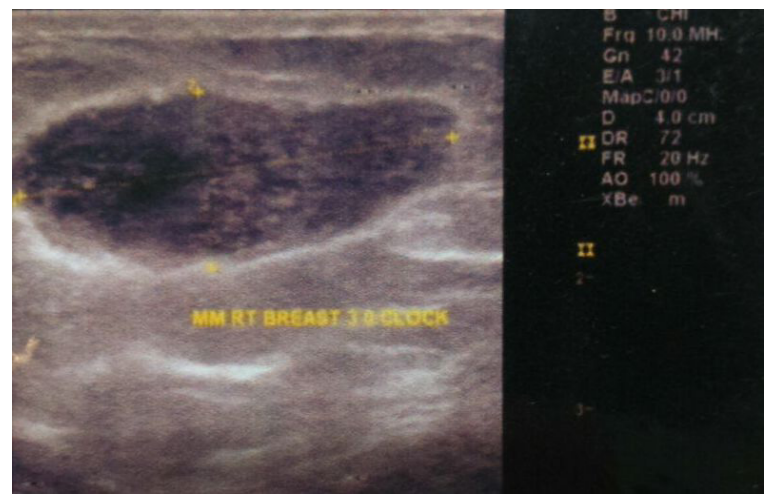

Fig.2: Breast mammography showing oval irregular thick walled low level echo complex cystic mass at 3 O'clock position in retro-areolar position.

less than $0.1 \%$ of the mammary lesions examined via histology $[4,5]$. Usually women of the age group 20 and 50 years are affected [5].

The disease is classified as primary if the breast tissue is the primary foci of infection and secondary if the breast is affected secondary to dissemination from primary source either through lymphatic or hematogenous route [6], the primary form of the disease being very rare [7]. Breast tissue seems to be relatively resistant to tuberculous infection [8]. Multi-parity, lactation, trauma and past history of suppurative mastitis are the risk factors for tubercular mastitis [9]. Commonly the lump is found in the central or upper outer quadrant of the breast [10]. The mass may be fluctuant and often

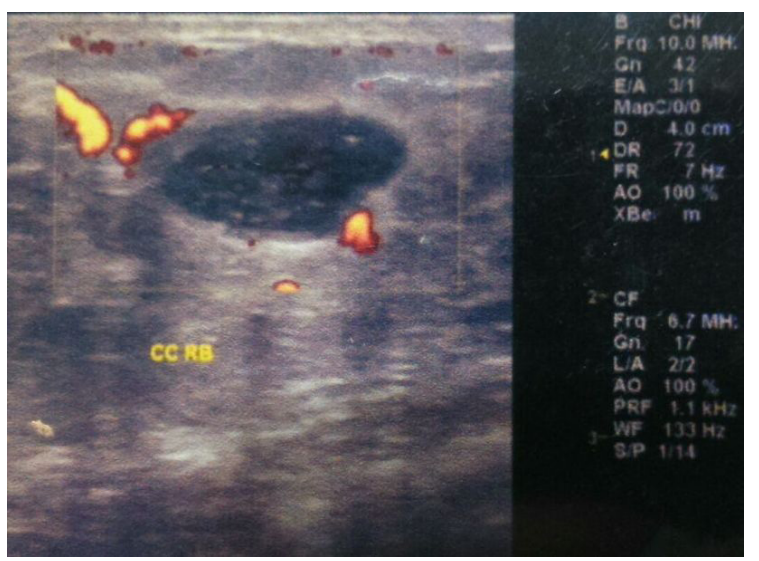

Fig.3: Mammography after two months showed reduction in size of abscess.

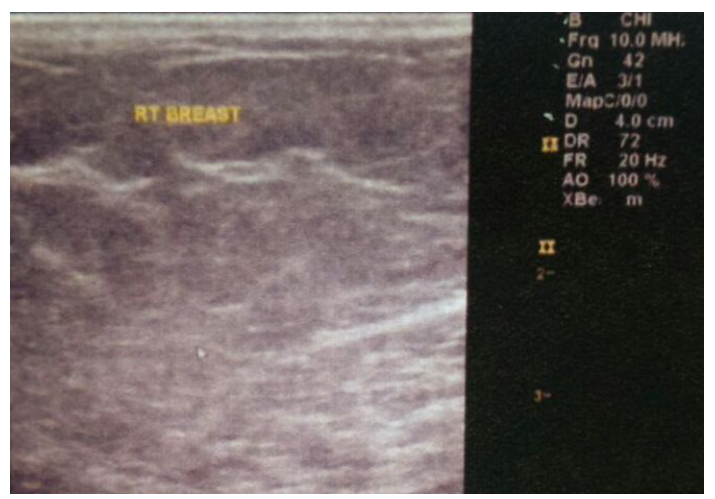

Fig.4: Mammography image showing resolution of abscess.

covered with indurated tissue. It is usually fixed to the skin and fistulization is not uncommon. Nipple and skin retraction may occur but breast discharge and pain are not seen commonly [11]. Unilateral involvement is common. Bilateral involvement is rare and may occur in upto $3 \%$ cases [2].

Breast tuberculosis was first classified into five different types by Mckeown and Wilkinson. Presently, it has been reclassified as nodular, disseminated and abscess varieties. The sclerosing type, mastitis obliterans and miliary variety are of historical importance. Nodular type is the most common and the lesion presents as a localized mass with extensive caseation. Disseminated type involves the whole breast with numerous 
sinuses. Breast abscess is often a common mode of presentation of breast tuberculosis, commonly in young women [12].

The gold standard in establishing the diagnosis is demonstration of the causative organism Mycobacterium tuberculosis in Z-N stain or in culture but is difficult to demonstrate [13]. Polymerase chain reaction as a diagnostic tool for breast tuberculosis is less often reported. However, PCR is by no means absolute in diagnosing tubercular infection as false negative results are still a probability [12]. Ultrasound is helpful for characterizing the ill-defined densities shown on mammography by exclusion of solid masses, but the findings of a hypo-echoic lesion with heterogeneous internal echoes and irregular borders are not specific [2]. Treatment involves administration of anti-tubercular therapy.

\section{Conclusion}

A high index of suspicion on clinical examination and pathological or microbiological confirmation of all suspected lesions are required for diagnosis of breast tuberculosis. Breast tuberculosis, though rare, should be considered as one of the differentials as it may be misdiagnosed as malignancy in the elderly population and pyogenic abscess in young females.

Contributors: RK, SiK: Manuscript writing and literature review; SaK, RK: Manuscript editing. SiK will act as guarantor. All authors approved the final version of the manuscript.

Funding: None; Competing interests: None stated.

\section{References}

1. Cooper A. Illustrations of the diseases of the breast. Part I. London: Longman, Rees, Orme, Brown, and Green; 1829. pp. 73.

2. Hale JA, Peters GN, Cheek JH. Tuberculosis of the breast: rare but still extant. Am J Surg. 1985;150:620624.

3. Tewari M, Shukla HS. Breast tuberculosis: diagnosis, clinical features, and management. Indian J Med Res. 2005;122:103-110.

4. Gupta V, Mohan H, Jain P, Singh S, Singla N. Tuberculous mastitis: A report of two cases in elderly females. Jpn J Infect Dis. 2006;59:279-280.

5. Zandrino F, Monetti F, Gandolfo N. Primary tuberculosis of the breast. A case report. Acta Radiol. 2000;41:61-63.

6. Daali M, Hssaida R. Had Primary tuberculosis of breast. Presse Med. 2001;30:431-433.

7. Zandrino F, Monetti F, Gandolfo N. Primary tuberculosis of the breast. A case report. Acta Radiol. 2000;41:61-63.

8. Alagaratnam TT, Ong GB. Tuberculosis of the breast. $\mathrm{Br}$ J Surg. 1980;67:125-126.

9. Chellaovi M, Taleb A, Chat L, Achaabane F, Alami D, Najid A, et al. Tuberculosis of breast; a case report. J Radiol. 2002;83:742-744.

10. Morsad F, Ghazli M, Boumzgon K, et al. Mammary tuberculosis: a series of 14 cases. J Gynaecol Obstet Biol Reprod. 2001;30:331-337.

11. Green RM, Ormerud LP. Mammary tuberculosis: rare but still present in the united kingsom. Int J Tuberc Lung Dis. 2000;4:788-790.

12. Kant S, Mahajan M, Verma SK: Tubercular Mastitis Mimicking Malignancy. The Internet Journal of Pulmonary Medicine. 2008;9(2).

13. O'Reilly M, Patel KR, Cummins R. Tuberculosis of breast presenting as carcinoma. Mil Med. 2000;165:800802 . 